\title{
Reversible cerebral vasoconstriction syndrome (RCVS): an interesting case report
}

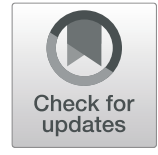

Mansoureh Togha ${ }^{1,2^{*}}$ (D), Mahsa Babaei ${ }^{3}$ and Parvin Ganji Ghelichi ${ }^{4}$

\begin{abstract}
Background: Reversible Cerebral Vasoconstriction Syndrome is a condition of transient cerebral vascular spasms, which usually presents with recurrent thunderclap headaches and recovers within 3 months. Several probable triggers and underlying factors, such as sex hormones, vasoactive drugs, head trauma or surgery, and tumors, have been implicated.

Case presentation: In this paper, we present a 53-year-old woman with thunderclap headaches and normal lab tests who was radio-clinically diagnosed with reversible cerebral vasoconstriction syndrome and treated accordingly. Then, she experienced the recurrence of RCVS after about 2 years and headaches after 1 year in association with high blood pressure, high blood sugar, hypothyroidism, hyperlipidemia, and a urine metanephrine level of 5 times higher than the normal limit, suggesting a diagnosis of pheochromocytoma. After confirmation of the diagnosis with further imaging studies, surgical removal of the tumor resolved all the signs and symptoms.

Conclusion: Often underdiagnosed, pheochromocytoma could be an important condition associated with RCVS. It is important for clinicians to bear this diagnosis in mind while dealing with similar cases of recurrent thunderclap headaches.
\end{abstract}

Keywords: Pheochromocytoma, Reversible cerebral vasoconstriction syndrome, Thunder-clap headache

\section{Introduction}

Thunderclap headache $(\mathrm{TCH})$ is defined as a highintensity headache with an abrupt onset, reaching its peak intensity within less than one minute and lasting for more than five minutes. This type of headache is usually indicative of serious underlying causes and is rarely a primary disorder [1].

Reversible Cerebral Vasoconstriction Syndrome (RCVS) is a condition of vascular spasms in the brain, mainly presenting with a recurrent, severe, diffuse type of $\mathrm{TCH}$ that may be present or recurrent for one or 2 weeks from its onset and usually resolves within

\footnotetext{
* Correspondence: togha1961@gmail.com

${ }^{1}$ Neurology ward, Sina Hospital, School of Medicine, Tehran University of Medical Sciences, Tehran, Iran

${ }^{2}$ Headache department, Irainian Center of Neurological Researches, Institute of Neuroscience, Tehran University of Medical Sciences, Tehran, Iran Full list of author information is available at the end of the article
}

3 months. This is a poorly understood condition, which can be associated with focal neurological deficits and seizures. The "string of beads" appearance on angiography, consisting of segmental vasodilations and vasoconstrictions, is the radiological characteristic of RCVS [1]. RCVS [1, 2] and Subarachnoid Hemorrhage (SAH) [2] are the most common causes of $\mathrm{TCH}$, making it a medical emergency requiring immediate consideration $[1,2]$.

Several triggers and underlying factors contribute to formation of RCVS and its final management is based on the recognition and resolution of the underlying cause and avoidance of probable triggers [3-6]. Accordingly, catecholamine secreting tumors, specifically pheochromocytomas, have been reported as rare but important causes of RCVS [3, 7].

Pheochromocytoma is a tumor of chromaffin cell that develops in the adrenal medulla. Manifestations of functional pheochromocytomas are mainly due to excessive

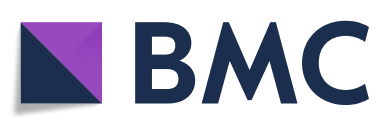

(c) The Author(s). 2021 Open Access This article is licensed under a Creative Commons Attribution 4.0 International License, which permits use, sharing, adaptation, distribution and reproduction in any medium or format, as long as you give appropriate credit to the original author(s) and the source, provide a link to the Creative Commons licence, and indicate if changes were made. The images or other third party material in this article are included in the article's Creative Commons licence, unless indicated otherwise in a credit line to the material. If material is not included in the article's Creative Commons licence and your intended use is not permitted by statutory regulation or exceeds the permitted use, you will need to obtain permission directly from the copyright holder. To view a copy of this licence, visit http://creativecommons.org/licenses/by/4.0/ The Creative Commons Public Domain Dedication waiver (http://creativecommons.org/publicdomain/zero/1.0/) applies to the data made available in this article, unless otherwise stated in a credit line to the data. 
amounts of catecholamine release [8]. A diagnosis is usually made based on clinical manifestations and lab tests and the final management usually includes surgical removal of the tumor [8-12].

We present a case of $\mathrm{TCH}$ with a diagnosis of recurrent RCVS associated with pheochromocytoma. This case posed a diagnostic challenge and took 3 years to reach a final diagnosis and identify the underlying cause of thunderclap headache, which was pheochromocytoma. Interestingly, all signs and symptoms resolved after tumor resection.

\section{Case presentation}

About 6 years ago, a 53-year-old woman who was an expert gynecologist presented with severe headaches for which she was admitted to the neurology ward of the hospital where she was working. She complained about three episodes of severe, sudden-onset headaches in the last 2 weeks. Each headache episode started spontaneously, reached its maximum intensity within $1 \mathrm{~min}$, and lasted for 5 to $10 \mathrm{~min}$. The headache was pulsatile starting from the occipital area extending to the frontal region. She also complained about less severe headaches with a shorter duration in the next days, mainly triggered by the Valsalva maneuver. The pain was not positional and did not respond to any analgesics or opioids.

On admission, her physical and neurological examinations including fundoscopic evaluation were normal. Brain Magnetic Resonance Imaging (MRI) with and without contrast, Magnetic Resonance Arteriography (MRA) and Magnetic Resonance Venography (MRV) were unremarkable.

A 24-h Ambulatory Blood Pressure Monitor (ABPM) recorded a mean blood pressure of $110 / 70$ that reached its peak at 180/120 during her headache attacks. The heart rate was normal.

Hematological tests and 24-h urine vanillylmandelic acid (VMA) were all normal. Abdominopelvic sonography also reported normal findings. The patient did not consent to a lumbar puncture.

Because of repeated attacks of thunderclap headache and ruling out $\mathrm{SAH}$ and other possible causes of $\mathrm{TCH}$, a diagnosis of RCVS was made and IV magnesium and oral verapamil were initiated with careful cardiac monitoring. TCH did not repeat and other milder headache attacks significantly improved and resolved thereafter. The patient was discharged from the hospital with oral verapamil and magnesium. She complained about dizziness and presyncope attacks for 1 month after discharge that resolved spontaneously. Her medications were tapered off gradually and discontinued.

After 2 years of being asymptomatic, she started to experience tachycardia and tachypnea while lying down from a sitting position. She felt cold in her head and developed facial pallor or flashing after experiencing anger, stress, tiredness, or hot temperature. She also experienced dizziness on standing occasionally. One month later, she repeatedly experienced $\mathrm{TCH}$-like attacks. Her maximum blood pressure was 200/140 occasionally at the time of the headache attacks and was normal in between. She underwent physical and neurologic exams, blood and urine sample tests, ABPM, ECG, IOP measurement, trans-Cranial Color Doppler (TCCD), and brain MRI, MRA, and MRV. There was a small hematoma in the right parietal lobe without edema and compression effect that was reported as a hemorrhagic infarct. In brain MRA, segmental arterial spasms were noted and increased velocity of Right Middle Cerebral Artery (RMCA), suggestive of vasospasm, was reported on TCCD. All other test results including those related to collagen vascular diseases were normal.

With a diagnosis of recurrent RCVS, which is a rare condition, oral administration of magnesium $600 \mathrm{mg} /$ day and verapamil $200 \mathrm{mg} /$ day was initiated. Medications improved her signs and symptoms but were not able to resolve them completely. Verapamil was tapered to a dose of $80 \mathrm{mg} /$ day orally within 4 months. In addition, magnesium administration was continued at a dose of $400 \mathrm{mg} / \mathrm{d}$. Two questions were unanswered regarding the patient's diagnosis: the repeated RCVS attacks, which is quite unusual, and the continuous need for verapamil and magnesium. Two years later, despite receiving the medications, she experienced recurrence of pulsatile headache attacks of short duration (about $10 \mathrm{~min}$ ) that were less severe than previous bouts. Sedatives were prescribed and she was advised to rest, avoid stress, and sleep well, but none of them could relive the headaches.

Unexpectedly, after 6 months, she developed hypertension and her lab tests revealed high blood sugar. She also developed general skin pruritus and unusual pustules. Further investigations revealed that the urinary metanephrine level was 5 times higher than the normal range, indicated a diagnosis of pheochromocytoma. Additionally, Computerized Tomography (CT) scan revealed a mass in the right adrenal gland. Phenoxybenzamine was initiated to control and reduce her blood pressure in order to prepare the patient for surgery. Fourteen days later, laparoscopic hemi-adrenalectomy was performed, and verapamil was discontinued after the surgery. Thereafter, all the manifestations, including headache attacks and hypertension, resolved completely and all the routine hematological and urine tests, especially blood sugar became normal.

\section{Discussion}

RCVS mostly affects middle aged women [13] and is believed to be more prevalent than what is reported in the literature [4]. Therefore, it is commonly underdiagnosed $[4,14,15]$. Several precipitating factors including 
exertion [1, 3], coughing [3], sexual activity [1, 3], bathing [3], and Valsalva maneuver [1], a number of underlying causes such as pregnancy related conditions [3, 7], postpartum $[1,3,4,7]$, exposure to vasoactive drugs [1, $3,4,7]$, use of licit or illicit drugs [1, 4, 7], catecholamine excess $[3,4,7]$, head and neck related disorders including trauma, head and neck surgery, carotid endarterectomy, and cervical artery dissection [3, 7], and various medical conditions such as exposure to immunosuppressant drugs or blood products $[3,7]$ have been implicated in RCVS.

As described earlier in the introduction section, RCVS mainly presents with TCH-like headaches [1]. Besides, any new $\mathrm{TCH}$ is a medical emergency prompting further investigations $[1,2,16]$, including careful physical and neurologic examination, a brain CT scan without contrast as soon as possible, and a lumbar puncture in case of an inconclusive CT scan to evaluate SAH. After exclusion of $\mathrm{SAH}$, further evaluations are needed to find the underlying cause $[2,17,18]$, because according to $\mathrm{ICDH} 3$, there is poor evidence suggesting that $\mathrm{TCH}$ is a primary disorder. Therefore, primary $\mathrm{TCH}$ is a diagnosis of last resort and should be mentioned after satisfactory exclusion of organic underlying causes, mainly with normal brain imaging as well as observation of normal brain vessels and normal Cerebrospinal Fluid (CSF) [1].

Diagnosis of RCVS is based on clinical manifestations and radiological findings including the "string of beads" appearance on angiography [1]. Lab tests are usually normal in RCVS [2]. Similarly, radiologic studies can be normal in a number of cases [19], especially during the first week of symptoms. However, any new headache fulfilling the criteria of RCVS with normal imaging and lab test results can be regarded as an "Acute Headache Probably Attributed to RCVS" [1]. If the clinical and radiological findings are inconclusive or the underlying cause is still missing, routine blood tests, urinalysis, urine vanillylmandelic acid and 5-hydroxyindoleacetic acid levels, serum and urine toxicology screens, ESR, CRP, infectious and rheumatological panel tests, and CSF examination are indicated [5].

Repeated headache attacks can be triggered by the Valsalva maneuver or exertion in RCVS [20]. These factors also triggered headache attacks in our patient. Therefore, such headache episodes do not preclude RCVS.

Management of RCVS includes treatment of the underlying cause(s) and avoidance of triggers and precipitants. Calcium channel blockers such as nimodipine and verapamil are used to relieve the headache and acute symptoms. They can also prevent further problems [3-6].

Headache may persist after the resolution of RCVS signs and symptoms; however, there are limited studies in this regard and the headache frequency and type are not well defined yet. Our patient had mild persistent headaches after the second bout of RCVS.

Complications of RCVS include ischemic stroke and intracranial hemorrhages $[3,4,14]$. However, the longterm outcome of RCVS is usually excellent $[5,13,14]$. A number of studies have reported a low risk of recurrence for RCVS in the long term [20], which is usually due to re-exposure to RCVS triggers [5, 15, 21]. Nonetheless, some authors believe that the risk of recurrence is underestimated. In case of RCVS recurrence, a comprehensive evaluation is necessary for RCVS, as explained earlier in detail, to find the underlying cause for appropriate management [15].

Vasoactive substances and catecholamine excess have been categorized as the most important precipitants of RCVS [3, 7], and diagnostic evaluation of RCVS includes these entities [5]. In our case, recurrence of thunderclap headaches after 3 years and repeated investigations suggested that pheochromocytoma was the underlying cause of RCVS, and the signs and symptoms completely resolved with proper management of pheochromocytoma.

According to the literature and our case, functional pheochromocytomas have diverse manifestations, such as hypertension, orthostatic hypotension, hyperhidrosis, palpitation, tachycardia, facial pallor and rarely flushing, fever, anxiety and panic attacks, severe constipation, etc., which are caused by excessive amounts of catecholamine release $[8,22,23]$. It is important for clinicians to keep pheochromocytoma in mind as a differential diagnosis for such diverse manifestations. Measurement of 24-h urine vanillylmandelic acid is the most sensitive initial test for diagnosis of pheochromocytoma [24]. CT scan and MRI are used for localization and further assessment of tumor characteristics. Further investigations such as metaiodobenzylguanidine (MIBG) scintigraphy might be used depending on the case. The best cure for pheochromocytomas, especially functional and non-metastasized ones, is to remove them surgically $[8,11,12]$.

Patients should receive $\alpha 1$-blockers such as phenoxybezamine for 10-14 days prior to surgery to avoid hypertensive crisis. Calcium channel blockers and $\beta$-blockers can be used as alternatives or adjunct treatments to prevent tachycardia and disrhythmias. In our case, verapamil and phenoxybenzamine were administered prior to surgery. Laboratory tests ( 1 month later, 6 months later, 1 year later, and then annually) and imaging studies (1 year after the operation) are necessary postoperatively $[11,12]$. About $10 \%$ of pheochromocytomas metastasize to other organs requiring different, case-based diagnostic and therapeutic approaches [8].

Pre-syncope attacks were associated with pheochromocytoma in our patient, which has been reported in previous studies. Some studies have attributed it to the effects of dopamine produced by some pheochromocytomas and 
paragangliomas [25-27]. Another study attributed hypotension and syncope in pheochromocytoma to excess epinephrine secretion and volume depletion [28]. Accordingly, several studies have reported that pre-syncope attacks might occur because of transient autonomic dysregulations caused by intermittent excessive secretion of catecholamines [29] or due to altered sympathetic vascular modulation [30]. Another suggested hypothesis is that chronic norepinephrine secretion from phaochromocytoma downregulates the vascular adrenergic receptors causing orthostatic hypotension. Then, it results in reflex stimulation of central sympathetic discharge and causes a further rise in plasma norepinephrine, which aggravates the adrenergic receptor downregulation [31].

Another interesting finding in our patient, in line with previous case reports, was the association of intracranial hemorrhages and ischemic events with pheochromocytoma [32-34].

To the best of our knowledge, three cases of $\mathrm{TCH}$ associated with pheochromocytoma [35-37], and four cases of RCVS accompanied by pheochromocytoma [35, 38-40] have been reported in the literature. This emphasizes the need of further investigation of the relationship of RCVS and TCH with pheochromocytoma and excessive catecholamine production indicating the importance of including pheochromocytoma in the differential diagnosis of the underlying causes of RCVS or thunderclap headache, especially in case of recurrence, even if the initial investigations are unremarkable.

\section{Conclusion}

Pheocromocytoma has many different manifestations. As stated in this paper and in line with other previous studies, RCVS is a growing manifestation of pheocromocytoma and clinicians should evaluate patients presenting with RCVS for the possibility of an underlying pheochromocytoma.

\section{Authors' contributions \\ MT made the diagnosis and is responsible for the case management, writing the first draft, editing the manuscript and approval of the final version of the manuscript. $\mathrm{MB}$ contributed in writing and editing the manuscript and approval of the final manuscript. PGG contributed in completing the information related to the case. The author(s) read and approved the final manuscript.}

\section{Funding}

None of the authors have received any funding for this study.

\section{Availability of data and materials}

Data is available with corresponding author upon request.

\section{Declarations}

\section{Consent for publication}

Written informed consent was obtained from the patient for publication of this case report and accompanying images.

\section{Competing interests}

All authors declare that they have no conflict of interests in this study.

\section{Author details}

'Neurology ward, Sina Hospital, School of Medicine, Tehran University of Medical Sciences, Tehran, Iran. ${ }^{2}$ Headache department, Irainian Center of Neurological Researches, Institute of Neuroscience, Tehran University of Medical Sciences, Tehran, Iran. ${ }^{3}$ Department of Medicine, Shahid Beheshti University of Medical Sciences, Tehran, Iran. ${ }^{4}$ Department of medicine,

Division of obstetrics \& Gynecology, Milad hospital, Tehran, Iran.

Received: 29 December 2020 Accepted: 12 March 2021

Published online: 06 April 2021

\section{References}

1. Headache Classification Committee of the International Headache Society (IHS) (2018) The international classification of headache disorders. 3rd edition. Cephalalgia 38(1):1-211.

2. Schwedt TJ (2015) Thunderclap Headache. Continuum 21(4):1058-1059.

3. Chen SPFJ, Wang SJ (2011) Reversible cerebral vasoconstriction syndrome: current and future perspectives. Expert Rev Neurother 11(9):1265-1276. https://doi.org/10.1586/ern.11.112

4. Ducros ABM, Porcher R, Sarov M, Valade D, Bousser MG (2007) The clinical and radiological spectrum of reversible cerebral vasoconstriction syndrome: a prospective series of 67 patients. Brain. 130(12):3091-3101. https://doi. org/10.1093/brain/awm256

5. Singhal ABTM (2017) Reversible Cerebral Vasoconstriction Syndromes. In: BJ $I L R$, Leary M, Lo E, Thomas A, Yenari M, Zhang J (eds) Primer on Cerebrovascular Diseases, 2nd edn. Elsevier Science, pp 507-513

6. Gupta S, Zivadinov R, Ramasamy D, Ambrus J (2013) Reversible cerebral vasoconstriction syndrome in antiphospholipid antibody syndrome (APLA): the role of centrally acting vasodilators. Case series and review of literature. Clin Rheumatol 33(12):1829-1833. https://doi.org/10.1007/s10067-013-2434-9

7. Ducros AWW (2016) The typical thunderclap headache of reversible cerebral vasoconstriction syndrome and its various triggers. Headache. 56(4):657673. https://doi.org/10.1111/head.12797

8. dKR TAS, G1II A, Kawashima A, Kimura N, Komminoth P et al (2017) Tumours of the adrenal medulla and extra-adrenal paraganglia. In: OR LRV, Kloppel G, Rosai J (eds) WHO Classification of Tumours of Endocrine Organs, 4th edn. IARC Press; Lyons, France, p 184

9. Remine WHCG, Van Heerden JA, Sheps SG, Harrison EG (1974) Current management of pheochromocytoma. Ann Surg 179(5):740-748. https://doi. org/10.1097/00000658-197405000-00029

10. Lucon AMPM, Mendonca BB, Halpern A, Wajchenbeg BL, Arap S (1997) Pheochromocytoma: study of 50 cases. J Urol 157(4):1208-1212. https://doi. org/10.1016/S0022-5347(01)64925-5

11. Farrugia FAMG, Tzanetis P, Charalampopoulos A, Misiakos E, Zavras N (2017) Pheochromocytoma, diagnosis and treatment: review of the literature. Endocr Regul 51(3):168-181. https://doi.org/10.1515/enr-2017-0018

12. Davison ASJD, Ruthven S, Helliwell T, Shore SL (2018) Clinical evaluation and treatment of phaeochromocytoma. Ann Clin Biochem 55(1):34-48. https:// doi.org/10.1177/0004563217739931

13. Choi HA, Lee MJ, Choi H, Chung CS (2017) Characteristics and demographics of reversible cerebral vasoconstriction syndrome: a large prospective series of Korean patients. Cephalalgia. 38(4):765-775. https://doi. org/10.1177/0333102417715223

14. Patel SD, Topiwala K, Saini V, Patel N, Pervez M, Al-Mufti F, Hassan A, Khandelwal P, Starke PM (2021) Hemorrhagic reversible cerebral vasoconstriction syndrome: a retrospective observational study. J Neurol 268(2):632-639. https://doi.org/10.1007/s00415-020-10193-y

15. Chen SPFJ, Lirng JF, Wang YF, Wang SJ (2015) Recurrence of reversible cerebral vasoconstriction syndrome. Neurology. 84(15):1552-1558. https:// doi.org/10.1212/WNL.0000000000001473

16. Kunchok A, Castley HC, Aldous L, Hawke SH, Torzillo E, Parker GD, Halmagyi GM (2018) Fatal reversible cerebral vasoconstriction syndrome. J Neurol Sci 385:146-150. https://doi.org/10.1016/j.jns.2017.12.009

17. TJ. S (2013) Thunderclap headaches: a focus on etiology and diagnostic evaluation. Headache. 53(3):563-569. https://doi.org/10.1111/head.12041

18. Long D, Koyfman A, Long B (2019) The Thunderclap Headache: Approach and Management in the Emergency Department. J Emerg Med 56(6):633641. https://doi.org/10.1016/j.jemermed.2019.01.026.

19. Boysson H, Parienti J,, Mawet J, Arquizan C, Boulouis G, Burcin C, Naggara O, Zuber M, Touzé E, Aouba A, Bousser MG, Pagnoux C, Ducros A (2018) Primary 
angiitis of the CNS and reversible cerebral vasoconstriction syndrome. Neurology 91(16). https://doi.org/10.1212/WNL.0000000000006367

20. Ling YH, SP Chen (2020) Narrative Review: Reversible Cerebral Vasoconstriction Syndrome. Curr Pain Headache Rep 24(12):74. https://doi. org/10.1007/s11916-020-00908-1

21. Boitet R, Gaalon S, Duflos C, Marin G, Mawet J, Burcin C, Roos C, Fiedler U, Bousser MG, Ducros A (2020) Long-Term Outcomes After Reversible Cerebral Vasoconstriction Syndrome. Stroke 51(2):670-673. https://doi.org/1 0.1161/STROKEAHA.119.027703

22. Hamidi OYW, Gruber L, Smestad J, Yan Q, Ponce OJ (2017) Outcomes of patients with metastatic Phaeochromocytoma and Paraganglioma: a systematic review and meta-analysis. Clin Endocrinol 87(5):440-450. https:// doi.org/10.1111/cen.13434

23. Muir Manger WGR (1977) Pheochromocytoma: springer-Verlag New York Inc. https://doi.org/10.1007/978-1-4612-9900-4

24. Ganesh HKAS, Goerge J, Bandgar TR, Menon PS, Shah NS (2009) Pheochromocytoma in children and adolescents. Indian J Pediatr 76(11): 1151-1153. https://doi.org/10.1007/s12098-009-0287-7

25. GD DLA (2005) Dopamine-secreting Pheochromocytomas: in search of a syndrome. World J Surg 29(7):909-913. https://doi.org/10.1007/s00268-005-7860-7

26. Eisenhofer GGD, Sullivan P, Csako G, Brouwers FM, Lai EW (2005) Biochemical and clinical manifestations of dopamine-producing Paragangliomas: utility of plasma Methoxytyramine. J Clin Endocrinol Metab 90(4):2068-2075. https://doi.org/10.1210/jc.2004-2025

27. Foo SHCS, Ananda V, Rajasingam V (2010) Dopamine -secreting phaeochromocytomas and paragangliomas: clinical features and management. Singap Med J 51(5):89-93

28. Ueda TON, Matsumoto A, Miyazaki H, Ohmura H, Kikuchi T (2005) Pheochromocytoma presenting as recurrent hypotension and Syncope. Intern Med 44(3):222-227. https://doi.org/10.2169/internalmedicine.44.222

29. Zweiker RTM, Eber B, Schumacher M, Fruhwald FM, Lipp R (1997) Bradydysrhythmia-related presyncope secondary to pheochromocytoma. J Intern Med 242(3):249-253. https://doi.org/10.1046/j.1365-2796.1997.00198.x

30. Munakata MAA, Imai Y, Noshiro T, Ito S, Yoshinaga K (1999) Altered sympathetic and vagal modulations of the cardiovascular system in patients with Pheochromocytoma: their relations to orthostatic hypotension. Am J Hypertens 12(6):572-580. https://doi.org/10.1016/S0895-7061(99)00026-6

31. Streeten DHPAG (1996) Mechanisms of orthostatic hypotension and tachycardia in patients with pheochrmocytoma. Am J Hypertens 9(8):760769. https://doi.org/10.1016/0895-7061(96)00057-X

32. Chuang HLHW, Hsueh C, Lin JN, Scott RM (2002) Spontaneous intracranial hemorrhage caused by Pheochromocytoma in a child. Pediatr Neurosurg 36(1):48-51. https://doi.org/10.1159/000048350

33. Douma SDM, Petidis K, Tsorlalis K, Papaefthimiou P, Kartali N (2008) Intracerebral hemorrhage as the presenting feature of concurrent Pheochromocytoma and Paragangliomas. J Clin Hypertens 10(12):941-944. https://doi.org/10.1111/j.1751-7176.2008.00051.x

34. Mazey RMKT, Ernst CB (1974) A syndrome resembling pheochromocytoma following a stroke. Report of a case. JAMA 230(4):575-577

35. English SWND (2019) Thunderclap headache and cerebral vasoconstriction secondary to Pheochromocytoma. JAMA Neurol 76(4):502-503. https://doi. org/10.1001/jamaneurol.2019.0001

36. Heo YEKH, Nam HW (2009) Thunderclap headache as an initial manifestation of phaeochromocytoma. Cephalalgia. 29(3):388-390. https:// doi.org/10.1111/j.1468-2982.2008.01738.x

37. Watanabe MTA, Shimano H, Hara H, Sugita S, Nakamagoe K (2010) Thunderclap headache without hypertension in a patient with pheochromocytoma. J Headache Pain 11(5):441-444. https://doi.org/10.1007/s10194-010-0234-z

38. Armstrong FSHG (1961) Segmental cerebral arterial constriction associated with pheochromocytoma: report of a case with arteriograms. J Neurosurg 18(6):843-846. https://doi.org/10.3171/jns.1961.18.6.0843

39. Madhok J, Kloosterboer A, Venkatasubramanian C, Mihm FG (2020) Catecholamine-induced cerebral vasospasm and multifocal infarctions in pheochromocytoma. Endocrinol Diabetes Metab Case Rep 2020(1):1-6

40. Pantoja-Ruiz CR-FA, Ocampo-Navia MI, Coral-Casas J (2020) Reversible cerebral vasoconstriction syndrome associated with a suprarenal mass Prague Med Rep 121(2):107-113. https://doi.org/10.14712/23362936.2020.9

\section{Publisher's Note}

Springer Nature remains neutral with regard to jurisdictional claims in published maps and institutional affiliations.

\section{Ready to submit your research? Choose BMC and benefit from:}

- fast, convenient online submission

- thorough peer review by experienced researchers in your field

- rapid publication on acceptance

- support for research data, including large and complex data types

- gold Open Access which fosters wider collaboration and increased citations

- maximum visibility for your research: over $100 \mathrm{M}$ website views per year

At $\mathrm{BMC}$, research is always in progress.

Learn more biomedcentral.com/submissions 